\title{
Corrosion Resistance Evaluation of Self-Healing Epoxy Coating Based on Dual-Component Capsules Containing Resin and Curing Agent
}

\author{
Alireza Safdari, ${ }^{1}$ Saied Nouri Khorasani $\mathbb{D}^{1},{ }^{1}$ Rasoul Esmaeely Neisiany $\left(\mathbb{D},{ }^{2}\right.$ \\ and Mohammad Sadegh Koochaki $\mathbb{D}^{1,3}$ \\ ${ }^{1}$ Department of Chemical Engineering, Isfahan University of Technology, Isfahan 84156-83111, Iran \\ ${ }^{2}$ Department of Materials and Polymer Engineering, Faculty of Engineering, Hakim Sabzevari University, Sabzevar 9617976487, Iran \\ ${ }^{3}$ Research and Development Department, Alvan Paint \& Resin Production Co., Tehran 13991-53611, Iran
}

Correspondence should be addressed to Saied Nouri Khorasani; saied@cc.iut.ac.ir and Rasoul Esmaeely Neisiany; r.esmaeely@hsu.ac.ir

Received 29 October 2020; Revised 28 February 2021; Accepted 5 March 2021; Published 18 March 2021

Academic Editor: Poornima Vijayan P

Copyright (C) 2021 Alireza Safdari et al. This is an open access article distributed under the Creative Commons Attribution License, which permits unrestricted use, distribution, and reproduction in any medium, provided the original work is properly cited.

In this study, a self-healing epoxy coating was prepared by incorporating a dual capsule healing system including epoxy resin and its amine-based curing agent. The emulsion electrospray technique was used for encapsulating the healing agents in poly(styrene coacrylonitrile) (SAN) as shell material. Characterizing the prepared microcapsules (MCs) by Scanning Electron Microscopy (SEM) revealed their spherical morphology with the particle size of $827 \mathrm{~nm}$ and $749 \mathrm{~nm}$ for epoxy and amine cores, respectively. Fourier Transform Infrared Spectroscopy (FT-IR) and thermogravimetric analysis (TGA) results confirmed successful encapsulation with no side chemical reaction between the encapsulated core and shell materials. The effects of embedding MCs on the physical and mechanical properties of the epoxy coating matrix were studied by pull-off adhesion, conical mandrel bending, and gloss tests. In addition, the prepared coatings' self-healing performance was evaluated by Electrochemical Impedance Spectroscopy (EIS) and potentiodynamic polarization (Tafel) experiments. The results revealed that the coating sample containing $1 \mathrm{wt} \%$ of core-shell MCs (a mixture of epoxy and amine-containing MCs with a 50:50 weight ratio) showed the best corrosion performance with $99 \%$ self-healing efficiency.

\section{Introduction}

Corrosion of metals is regarded as an important and challenging issue in many industries. According to recent studies, the global corrosion cost is estimated to be $3.1 \%$ of the countries' gross domestic product (GPD). Using polymeric barrier coatings is a well-known approach for metal corrosion prevention or deceleration. However, the most important limitation in polymers is the occurrence of microcracks in the matrix which leads to fracture if not controlled [1-4]. These faults cannot be repaired by conventional methods as they are not visible at the beginning. Therefore, in the 1980s, self-healing polymers were introduced as an effective solution for healing the microcracks and fracture prevention in order to achieve a better life span and safety of polymeric devices [5-9]. Self-healing materials are classified into two main classes including extrinsic [10-14] and intrinsic [15-17] systems based on the healing mechanism. Extrinsic systems based on the healing agent release have shown great efficiency among other methods [18].

Since the fracture in polymers begins at nanometer scales by crack formation and growth, reducing the size of capsules to submicron is crucial to enable the healing at the nanoscale as soon as the crack is formed and consequently prevent its growth [19-22]. Capsule based self-healing polymeric coatings utilize controlled release of active agents upon crack formation. These active healing agents are surrounded by shell capsules and added to the polymeric matrix. Crack formation in the coating matrix leads to the capsule rapture and subsequently healing agent release which will automatically repair 
the crack. White et al. reported the application of MCs based self-healing systems for repairing microcracks and increasing the life span of polymer composites [23]. Subsequently, several methods including in situ polymerization, solvent evaporation, and multistage emulsion polymerization have been employed to encapsulate healing agents within the micro/nanocapsules, while these methods are costly, timeconsuming, and need for purification. Recently, electrospinning and electrospray have been used for the encapsulation healing agents within nanofibers or MCs to address the abovementioned shortcomings [24, 25]. Park et al. encapsulated bicomponent dimethylsiloxane in a polyvinylpyrrolidone shell in two distinct steps using the coaxial electrospinning method. The resulted core-shell nanofibers were placed on a steel surface prior to the application of an acrylic-urethane coating on them. The self-healing ability of the system was tested [26]. Lee et al. reported the preparation of a selfhealing silicone-based coating by encapsulating bicomponent dimethylsiloxane in a polyacrylonitrile shell through emulsion electrospinning and adding them to a polydimethylsiloxane based coating [27]. Hia et al. encapsulated epoxy resin within alginate shell material through the emulsion electrospray method [28]. The average size of the prepared MCs was reported at $575 \pm 25 \mu \mathrm{m}$, and the MCs were employed to develop a self-healing composite with a healing efficiency of $50 \%$. Koochaki et al. developed a dual capsule healing system using polyetheramine and methylene diphenyl diisocyanate as a core within the SAN shell. The mentioned system showed high healing efficiency of $85 \%$ in an epoxybased coating [29]. The coaxial electrospray method was employed by Malekkhouyan et al. [24] to encapsulate Coconut-Oil-Based Alkyd Resin within SAN capsules with a mean capsule diameter of $708 \pm 252 \mathrm{~nm}$. The incorporation of the prepared capsules within epoxy resin provided a self-healing epoxy-based coating with a healing efficiency of 95\%. Recently, Ataei et al. [30] employed electrospray method for the preparation of core-shell capsules containing epoxy resin and its thiol-based curing agent as a dual component healing system for the development of a selfhealing epoxy-based coating.

In this research, the electrospray was the method to develop a dual capsule self-healing system based on epoxy resin and amine-based curing agents. For this purpose, epoxy resin and amine-based curing agents were separately encapsulated by SAN shell and subsequently incorporated in an epoxy matrix to prepare a dual-component self-healing anticorrosion coating. Considering the fast reaction between the epoxy resin and the amine group in curing agents at room temperature without any more required additional catalyst, the prepared system offers high healing efficiency at room temperature.

\section{Experimental Section}

2.1. Materials. SAN with an average molecular weight of $185000 \mathrm{~g} / \mathrm{mol}$ and $30 \%$ acrylonitrile content was purchased from Sigma-Aldrich to be used as capsule shell material. SAN was used as shell material due to its high capability for encapsulation of materials during electrospray and electro- spinning methods $[24,31]$ and excellent interaction with epoxy coating [32]. Dimethylformamide (DMF) was provided by DaeJung Co. and used as a solvent for preparing the polymer solution. Bisphenol F epoxy resin (Indox E210Inchem ltd) and cycloaliphatic polyamine (EPIKURE F205Hexion) were used as the core materials for preparing the dual capsule healing system. Bisphenol A epoxy resin (EPON 828-Hexion) and polyamidoamine curing agent (Merginamide A280-HOBUM Oleochemicals) were employed to prepare the coatings' matrix. 1,6-Hexanediol diglycdil ether (Indox ED180-Inchem ltd) was utilized as a reactive diluent for reducing the viscosity of the coating matrix.

\subsection{Sample Preparation}

2.2.1. Preparation of Core-Shell Capsules. At first, the SAN copolymer powder was placed in a vacuum oven at $50^{\circ} \mathrm{C}$ for 12 hours to remove any humidity and then dissolved in DMF at lab conditions by magnetic stirring for 24 hours to obtain a homogeneous shell solution $(4 \% \mathrm{w} / \mathrm{v})$. Afterwards, the core materials (Bisphenol F epoxy resin and cycloaliphatic polyamine) were separately added to the prepared shell solutions (1:1 core/shell weight ratio) and mixed by magnetic stirring for 2 hours followed by 20 minutes of sonication in an ultrasonic bath. The resulted mixtures were fed to $1 \mathrm{ml}$ syringes with a bundle 23 gauge needle. The electrospray process (Figure 1) was carried out at the broad ranges of applied voltage, feed rate, and the needle to collector distance to find the right conditions for preparing particles. The optimum values of electrospray parameters were obtained at an applied voltage of $24 \mathrm{kV}$ and a flow rate of $0.3 \mathrm{ml} \mathrm{h}^{-1}$. The distance between the needle tip and the collector was set at $15 \mathrm{~cm}$ to allow complete solvent evaporation during the spray process. Neat SAN particles were prepared by applying the same procedure for further characterizations.

2.2.2. The Preparation of Coatings for Corrosion and Mechanical Tests. To prepare the self-healing coatings, bisphenol A epoxy resin and the reactive diluent (1,6-hexanediol diglycidyl ether) were mixed with a $3: 1$ weight ratio. Then, the prepared capsules were added to the epoxy resin mixture and dispersed by mechanical stirring at $200 \mathrm{rpm}$ for $5 \mathrm{~min}$. Three different capsule contents (1, 5, and $10 \mathrm{wt} \%$ ) were added to the matrix to study their effects on the self-healing performance and coating characteristics. The weight ratio of epoxy-containing capsules to aminecontaining ones was kept $1: 1$ for all samples. The polyamidoamine curing agent was then added to the mixtures at a $100: 58$ of epoxy: amine weight ratio to cure the epoxy resin. The resulted mixtures were immediately coated on cleaned and sanded ST-37 steel plates with a thickness of $150 \mu \mathrm{m}$ by a thin-film applicator. The substrate composition was assessed according to ASTM E415 using an ARUN 2500 quantometer, and the results are presented in Table 1 [33]. Moreover, a neat coating including no MCs was applied with the same conditions as the control sample (CTRL) to study the effects of MC addition on the coating's characteristics. All the coatings were kept in the laboratory for 7 days to ensure complete curing. 

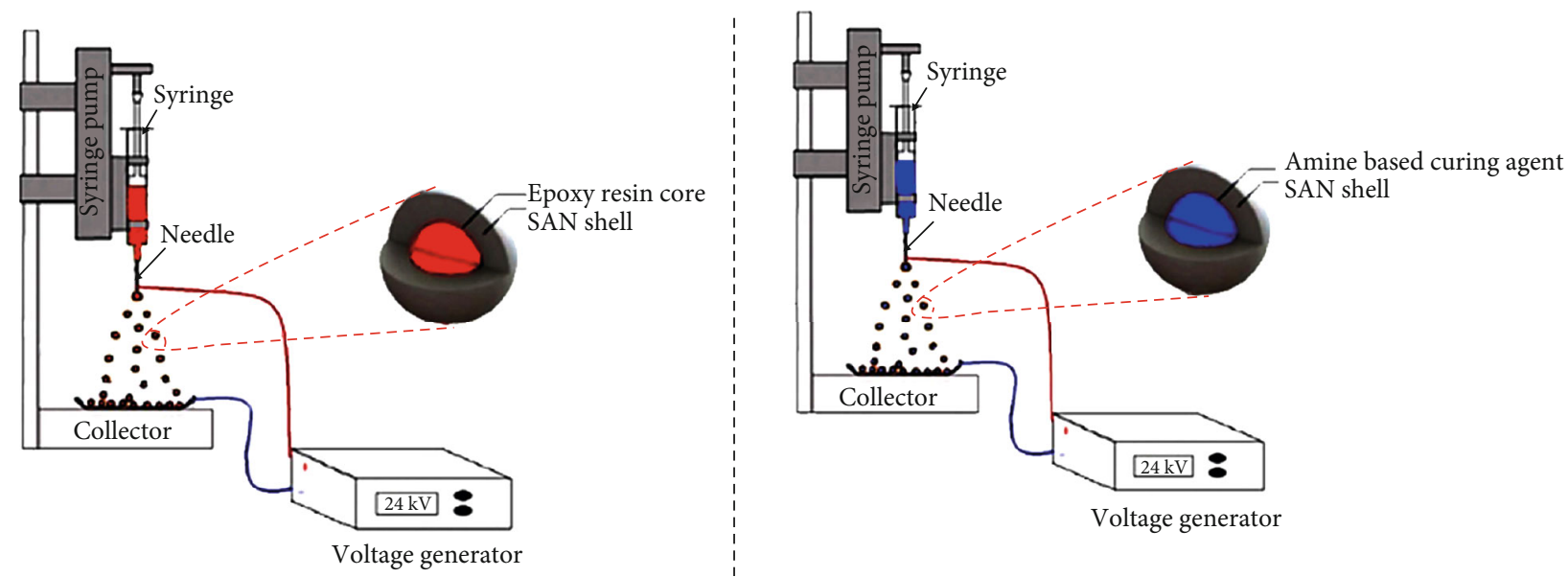

FIGURE 1: The schematic figure of employed electrospray set up to separately encapsulate epoxy and amine-based curing agent within SAN capsules.

TABLE 1: The St-37 substrate chemical composition.

\begin{tabular}{lccccccc}
\hline Elements & $\mathrm{Mn}$ & $\mathrm{C}$ & $\mathrm{Cr}$ & $\mathrm{Si}$ & $\mathrm{S}$ & $\mathrm{P}$ & $\mathrm{Fe}$ \\
\hline Weight percent (\%) & 0.512 & 0.112 & 0.045 & 0.028 & 0.008 & 0.007 & $\mathrm{Bal}$ \\
\hline
\end{tabular}

\subsection{Characterizations}

2.3.1. Characterization of the Prepared Capsules. FTIR (WQF-510A, RAYLEIGH, China) was used to characterize the chemical structure of the prepared capsules and their corresponding core and shell materials. The analysis was conducted using $\mathrm{KBr}$ pellets in a wavelength range of 4000 $400 \mathrm{~cm}^{-1}$.

SEM (Philips-XII30, Netherlands) was employed to study the morphology and particle size of the prepared capsules. All the samples were firstly gold-sputtered for 120 seconds at $10 \mathrm{mAh}$ before testing. The ImageJ software was used to determine the particle size and size distribution according to the SEM images. Moreover, transmission electron microscopy (2100F, JEOL, Japan) operating a $200 \mathrm{kV}$ Schottky field emitter was utilized to study the core-shell structure of the capsules which were sprayed on Lacey Formvar/carboncoated copper grids prior to testing.

To study the thermal stability and composition of the prepared capsules, thermogravimetric analysis (STA 6000 TGA system, Perkin Elmer, USA) was performed under a nitrogen atmosphere with a heating rate of $10^{\circ} \mathrm{C} / \mathrm{min}$ from 25 to $800^{\circ} \mathrm{C}$. To investigate the plausible reactions between the released healing agents, differential scanning differential analysis (DSC302, KBAHR-Germany) was used.

The encapsulation yield was measured for both epoxy and amine contained MCs by extraction method [31]. To perform the core extraction, each kind of MCs was crushed separately in a mortar to break their shell. Then, the core was washed from the crushed mixture with ethanol for several times, and the shell was filtered prior to being dried at $40^{\circ} \mathrm{C}$ for $24 \mathrm{~h}$ in an oven. The core content was then mea- sured, and the core content was determined according to Eq. (1) as follows:

$$
\% \text { Core content }\left(W_{\mathrm{ex}}\right)=\frac{\left(W_{\mathrm{ca}}-W_{\mathrm{sh}}\right)}{W_{\mathrm{ca}}} \times 100
$$

where $W_{\mathrm{ca}}$ and $W_{\mathrm{sh}}$ are associated with the weight of MCs and shell, respectively. Consequently, the encapsulation yield was determined for both core materials using Eq. (2):

$$
\% \text { Encapsulation yield }=\left(\frac{W_{\mathrm{ex}}}{W_{\mathrm{th}}}\right) \times 100 \text {. }
$$

The $W_{\text {th }}$ was calculated theoretically according to the weight ratio of core and shell materials in the syringe feed solution.

2.3.2. Characterization of Coatings. The pull-off adhesion test (PosiTest AT-M, Defelsko, USA) was carried out to evaluate the effect of capsules incorporation on the adhesion strength of the coatings to the steel substrate according to ASTM D4541. In addition, the conical mandrel bending test (Sheen Instruments, UK) was performed on the coatings in accordance with the ASTM D522-Test Method A, to study the effect of adding capsules on the coatings elongation properties. The gloss test was also conducted on the coated metal plates according to ISO 2813 by a multiangle gloss meter (SH260C, Sheen Instruments, UK) to study the effect of capsules addition on the coatings' surface roughness.

2.3.3. Evaluation of Corrosion Properties and Healing Efficiency. Different types of corrosion evaluation techniques 


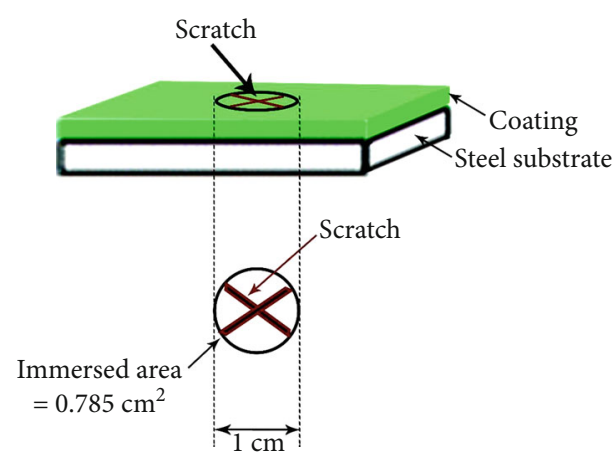

Figure 2: Scheme of the scratch dimensions in the coating to provoke the self-healing reaction.

were conducted to study the corrosion properties and assessing the self-healing performance of the prepared coatings. Potentiodynamic polarization (Tafel) and EIS tests were performed on the prepared coatings by an AMETEK Potentiostat/Galvanostat (PARSTAT 2273) to investigate their corrosion behavior and measuring the healing efficiency. An area of $0.785 \mathrm{~cm}^{2}$ (circle with $1 \mathrm{~cm}$ diameter) from the coating's surface was isolated by insulating the remaining surface with beeswax and then scratched in $\mathrm{X}$ shape deep to the substrate metal (Figure 2) using a scalpel blade to trigger the healing process. Then, the scratched coatings were kept in the lab conditions for 7 days to allow for the release of healing agents and their plausible healing reactions. Then, the scratched coatings were immersed in a $3.5 \% \mathrm{NaCl}$ solution for 14 days to stimulate seawater conditions.

A tri-electrode system $\left(0.785 \mathrm{~cm}^{2}\right.$ circular contact area) including an aqueous saturated calomel electrode (SCE) as the reference electrode and a platinum rod as the counter electrode was used to do the experiments. Measurements were conducted at the open circuit potential (OCP). The frequency range was varied from $10^{5}$ to $10^{-2} \mathrm{~Hz}$ at 10 points per decade sweeping frequency (logarithmic distribution) by a $10 \mathrm{mV}$ sinusoidal potential difference. Tafel experiments were also carried out at a $1 \mathrm{mV} \mathrm{s}^{-1}$ scan rate from $-1 \mathrm{~V}$ to $+1 \mathrm{~V}$ versus OCP.

Salt spray accelerated corrosion test was also carried out to assess the protection ability of the healing system. All of the coated steel plates were scratched by a scalpel blade and left in the lab for 7 days for plausible healing reaction prior to testing. The salt spray test was conducted for 72 hours according to ASTM B117.

\section{Results and Discussion}

3.1. Chemical Structure of the Core-Shell Capsules. FT-IR analysis was used to characterize the chemical structure of prepared capsules and making sure that there is no reaction between the shell and core during the encapsulation process. Figure 3 shows the FT-IR spectra of SAN (neat shell polymer), neat epoxy resin (core), and prepared core-shell capsules derived through the emulsion electrospray method. As shown in this image, for neat shell material, the absorbance peak at $2235 \mathrm{~cm}^{-1}$ is related to $\mathrm{C} \equiv \mathrm{N}$ in $\mathrm{SAN}$, and the peaks at $3040 \mathrm{~cm}^{-1}$ and $2930 \mathrm{~cm}^{-1}$ are attributed to the stretching

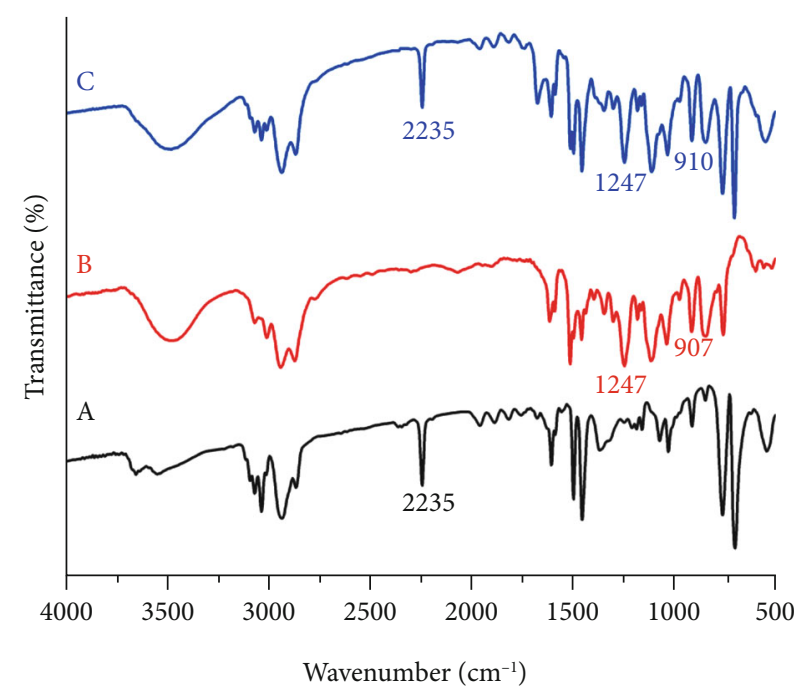

FIGURE 3: FT-IR spectra of (a) neat shell polymer (SAN), (b) neat epoxy resin, and (c) their corresponding core-shell capsules.

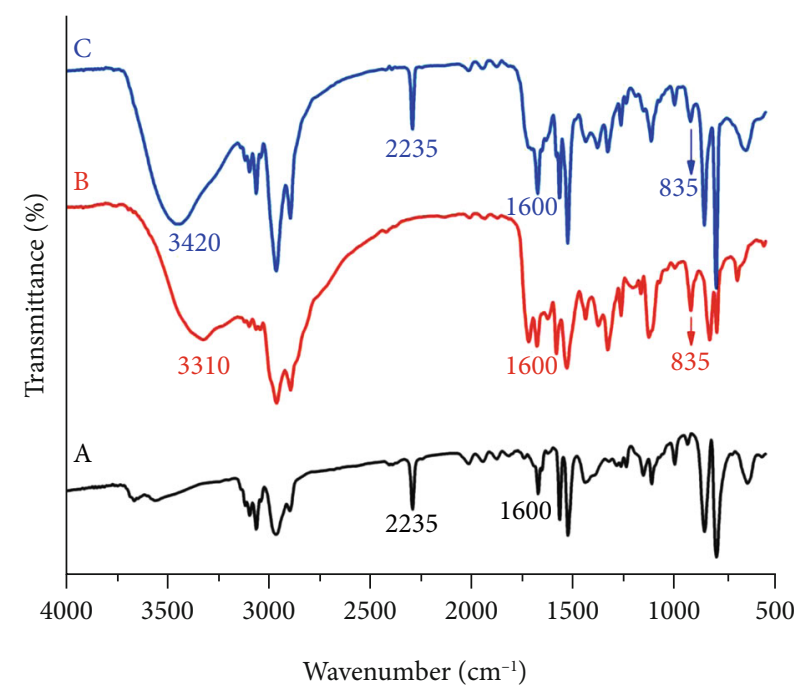

FIGURE 4: FT-IR spectra of (a) neat shell polymer (SAN), (b) neat curing agent (amine), and (c) their corresponding core-shell capsules.

vibrations of $\mathrm{CH} \mathrm{sp}^{2}$ and $\mathrm{CH} \mathrm{sp}^{3}$ [24]. In the neat epoxy spectrum, the absorbance peaks at $1247 \mathrm{~cm}^{-1}$ and $910 \mathrm{~cm}^{-1}$ correspond to C-O-C bond and epoxide groups, respectively [34]. The prepared core-shell capsules showed a broad absorption band at $3515 \mathrm{~cm}^{-1}$ associated with the $\mathrm{O}-\mathrm{H}$ group [35]. The presence of all aforementioned peaks attributed to neat SAN copolymer and neat epoxy resin in the spectrum of prepared core-shell capsules confirmed that these two components did not react during the encapsulation process.

Figure 4 shows the FT-IR spectra of SAN (neat shell polymer), neat amine curing agent (core), and prepared coreshell capsules derived through the emulsion electrospray method. As shown in Figure 4, absorption bands at 3310, 1600 , and $835 \mathrm{~cm}^{-1}$ correspond to stretching and bending vibrations of the amine group in the curing agent [34]. 


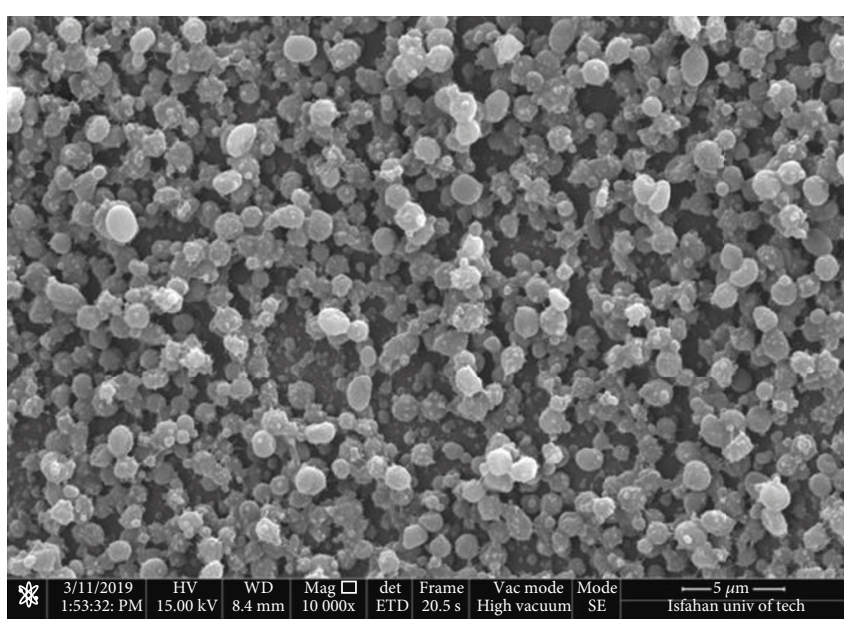

(a)

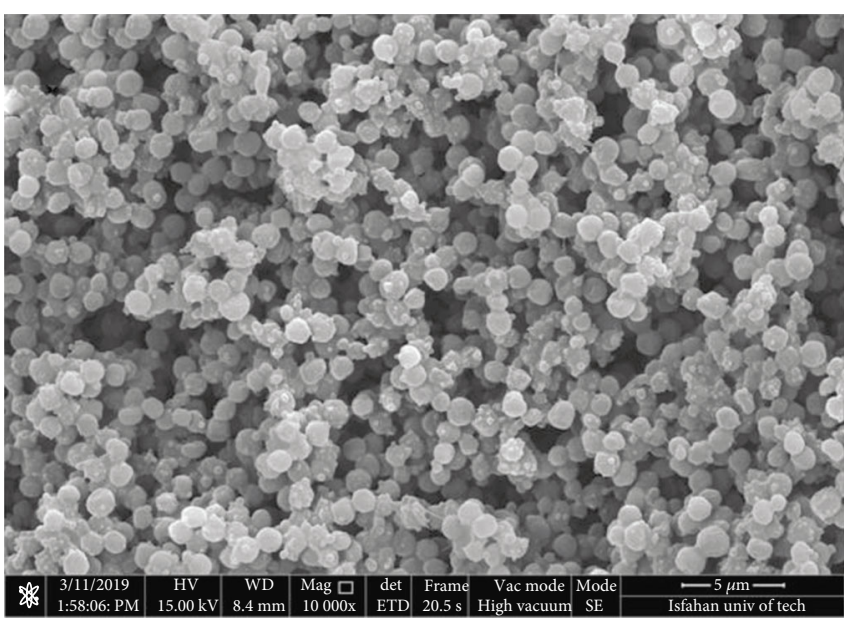

(c)

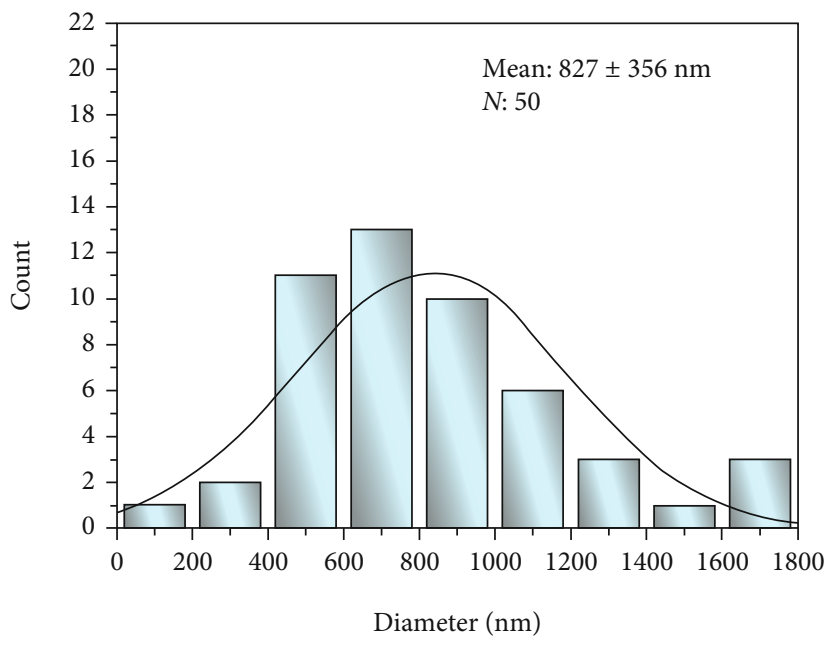

(b)

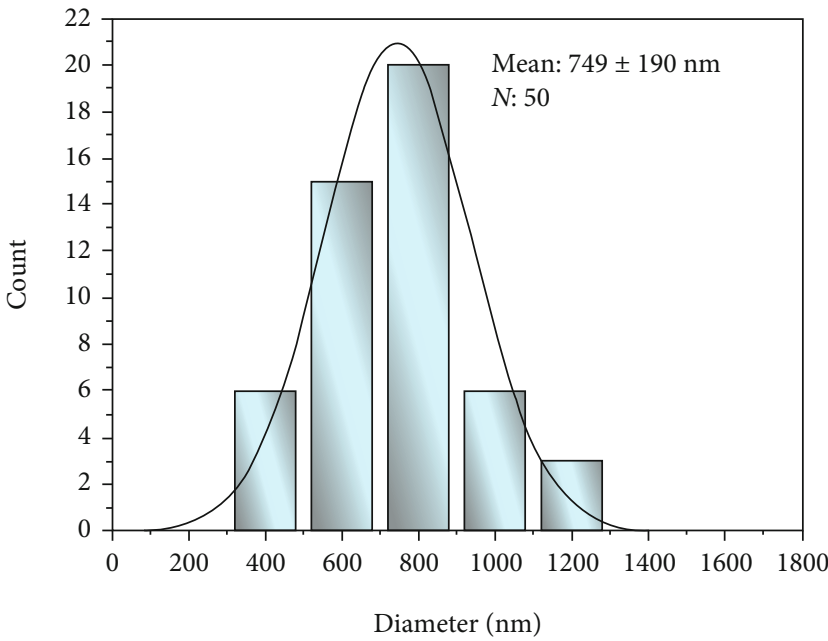

(d)

FIGURE 5: SEM images of the prepared MCs and their corresponding size distribution diagram for epoxy (a, b) and amine-based curing agent $(c, d)$ cores.

Similarly, the spectrum of prepared core-shell capsules reveals that all absorbance peaks of neat SAN and neat curing agent are presented simultaneously. It can be discerned, the $\mathrm{C} \equiv \mathrm{N}$ stretching vibration, at $2235 \mathrm{~cm}^{-1}$, of SAN shell and the amine stretching vibration of the core, $3300-3450 \mathrm{~cm}^{-1}$, are also present in the MCs, confirming that the core (amine) was successfully encapsulated in the shell polymer (polystyrene co-acrylonitrile) without any chemical reaction through the emulsion electrospray process [36].

3.2. Morphology and Size Distribution of the Prepared Capsules. Figure 5 shows the SEM images and size distribution of the prepared core-shell capsules. The mean particle size of the prepared capsules was calculated by 50 measurements using the Image J software. The mean particle size of the prepared capsules including epoxy resin and the amine core was calculated to be $827 \pm 356 \mathrm{~nm}$ and $749 \pm 190 \mathrm{~nm}$, respectively. According to the images, spherical MCs with rough outer surfaces were prepared for both amine and epoxy healing agents in the electrospray process at the aforementioned optimum conditions.

3.3. Thermal Stability. TGA tests were performed to determine the thermal stability of prepared MCs [37]. Figure 6(a) shows TGA curves of neat shell polymer (SAN), neat epoxy resin, and epoxy-containing MCs. As shown in Figure 6(a), thermal degradation of pure SAN occurred at $400-450^{\circ} \mathrm{C}$, which is related to the degradation of styrene groups. Also, the thermal degradation of the epoxy resin occurred in the temperature range of $200-500^{\circ} \mathrm{C}$. The epoxy resin containing core-shell MCs showed a two-step degradation at $200-500^{\circ} \mathrm{C}$. The first step is related to the degradation 


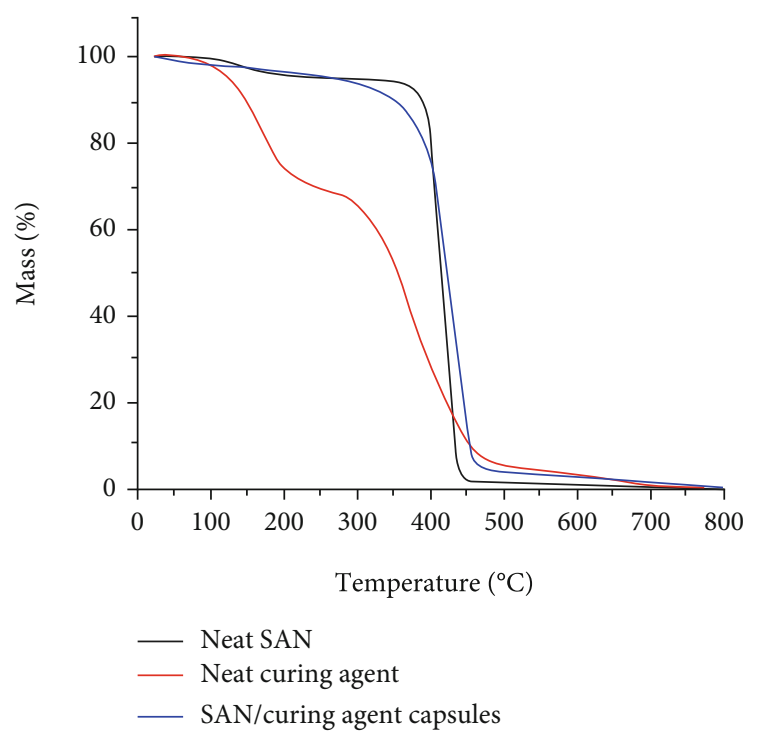

(a)

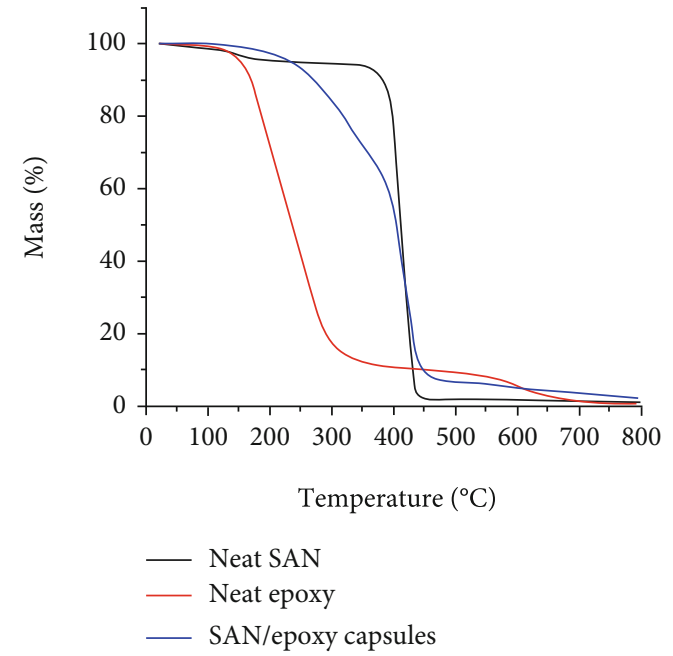

(b)

FIgURE 6: TGA thermograms of (a) neat SAN, neat epoxy resin, and epoxy-containing MCs (b) neat SAN, neat amine, and aminecontaining MCs.

of epoxy resin, and the second step is related to the decomposition of SAN.

Similarly, Figure 6(b) shows the TGA curves of neat shell polymer (SAN), neat amine, and amine-containing MCs. Neat amine showed a two-stage degradation of around 100 to $200^{\circ} \mathrm{C}$ and 350 to $500^{\circ} \mathrm{C}$. Amine-containing core-shell MCs showed the degradation of both amine core and SAN shell from 200 to $700^{\circ} \mathrm{C}$ which could be noted as a sign of successful core-encapsulation according to previous studies [38].

DSC tests were employed to study the possible curing reaction between the released healing agents from crushed prepared MCs. To provoke the MCs rapture and subsequent release of healing agents, amine and epoxy-containing MCs were mixed at $1: 1 \mathrm{wt}$. ratio and then crushed by mortar and pestle. Then, the resulted mixture was immediately tested by DSC to monitor any plausible reactions. As reported in previous studies, the reaction between amine and epoxy is exothermic [34]; therefore, the exothermic peak in the DSC curve of crushed capsules can be evidence of a healing reaction. Figure 7 shows the DSC curve of the (a) neat shell MCs, (b) mixture of neat core materials (epoxy and amine), and (c) mixture of crushed epoxy and amine contained MCs. The endothermic peak in the range of 120$125^{\circ} \mathrm{C}$ for neat shell can be attributed to the glass transition temperature of SAN. The reaction between the epoxy resin and amine in the nonencapsulated form is shown inline chart (b) by an exothermic peak at $100^{\circ} \mathrm{C}$. Moreover, the DSC curve for the mixture of epoxy resin and amine contained MCs (Figure $7(\mathrm{c})$ ) which are artificially crushed prior to testing shows an exothermic peak at $104^{\circ} \mathrm{C}$, which confirms the reaction between the relapsed healing agents after MC rapture.

Moreover, according to the extraction test results, the practical encapsulation yield was measured to be $73 \%$ and $67.8 \%$ for the epoxy and amine contained MCs, respectively. The results are summarized in Table 2.

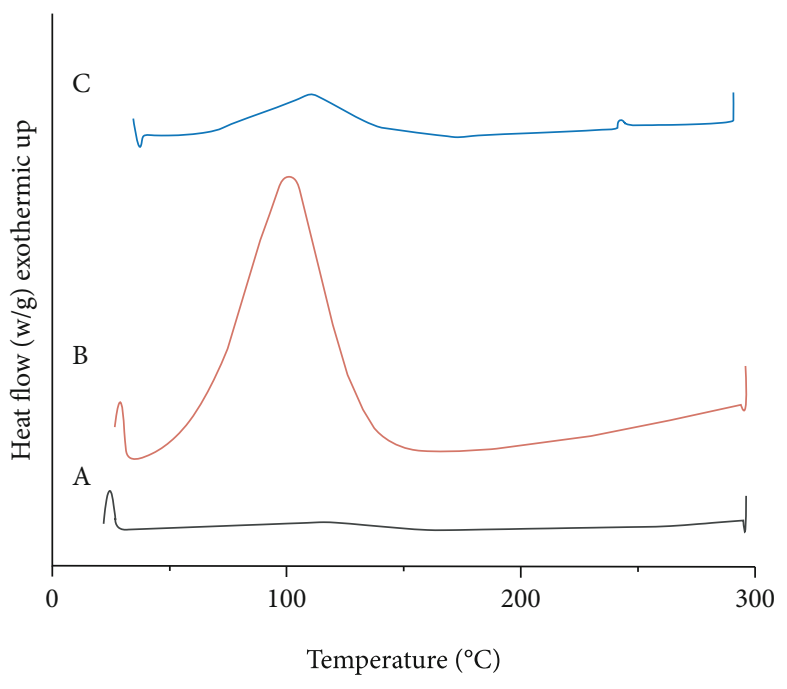

FIgURE 7: DSC curves of (a) neat SAN, (b) mixture of epoxy resin and amine in the nonencapsulated form, and (c) mixture of crushed epoxy resin and amine contained MCs.

TABLE 2: The determined results of core content and encapsulation yield.

\begin{tabular}{lccc}
\hline MCs & $W_{\text {ex }}(\%)$ & $W_{\text {th }}(\%)$ & $\begin{array}{c}\text { Encapsulation } \\
\text { yield (\%) }\end{array}$ \\
\hline Epoxy-contained MCs & 24.1 & 33.3 & 73 \\
Amine-contained MCs & 22.4 & 33.3 & 67.8 \\
\hline
\end{tabular}

3.4. Pull-off Adhesion Test. A pull-off adhesion test was used to study the effect of incorporating MCs on the coatings' adhesion strength to the steel substrate. The obtained results are summarized in Table 3. According to the results, MC 
TABLE 3: Adhesion strength results of the prepared coatings.

\begin{tabular}{lc}
\hline Sample & Adhesion strength (MPa) \\
\hline CTRL & $2.57 \pm 0.03$ \\
Coating containing 1 wt $\%$ MCs & $2.13 \pm 0.06$ \\
Coating containing $5 \mathrm{wt} \% \mathrm{MCs}$ & $1.7 \pm 0.06$ \\
Coating containing $10 \mathrm{wt} \% \mathrm{MCs}$ & $1.27 \pm 0.06$ \\
\hline
\end{tabular}

incorporation into the coating decreased the adhesion strength. This loss was the lowest for the sample containing $1 \% \mathrm{w}$ of MCs in comparison with the samples containing 5 and $10 \% \mathrm{w}$. The higher adhesion reduction in the samples with higher loading of MCs may be attributed to the agglomeration of MCs as well as their high surface area which will lead to more resin adsorption $[39,40]$.

3.5. Flexural Strength and Gloss Test of the Prepared Coatings. Conical mandrel bending tests were performed to study the effects of MCs addition on the flexibility and elongation of the prepared coatings. The results are presented as the coatings elongation at break (\%) in Table 4. According to the results, the addition of MCs reduced the elongation of the prepared coatings, which can be attributed to the reduced adhesion of the coating to the substrate, as well as the defects presented by incorporating the MCs into the matrix and their agglomeration [39].

The gloss (\%) measurement results of the coatings are summarized in Table 5. According to the results, the amount of gloss decreased by increasing the amount of MCs in the epoxy coatings. This loss is possibly attributed to the increased surface roughness caused by the addition and further agglomeration of MCs at higher concentrations [29].

3.6. Evaluation of Healing Reaction via Electrochemical Tests. A Potentiodynamic polarization test was employed to study the self-healing behavior of the scratched coatings after 14 days of immersion in a $3.5 \mathrm{wt} \% \mathrm{NaCl}$ solution. The results for the CTRL and MC contained coatings are presented in Figure 8. It can be seen that the incorporation of MCs to the matrix moved the corrosion potential (Ecorr) to more positive potentials and decreased the corrosion current density (icorr) which confirms the higher corrosion resistance and slower corrosion rate of healed scratched coatings $[29,41,42]$. According to the results, the sample containing $1 \%$ wt MCs had the highest corrosion potential as well as the lowest corrosion current density among the samples confirming its superior performance against corrosion. This resistance is attributed to the reaction between the healing agents (epoxy resin and amine) leaking from the raptured MCs during crack formation [43]. In other words, the performance of the utilized healing system restrained the possibility of ions attack at the interface of metal coating by consequence chemical reactions between the released epoxy resin and polyamine hardener (self-healing reaction). Moreover, the results reveal that increasing the concentration of MCs from $1 \%$ wt decreased the corrosion resistance of the prepared coatings. As mentioned before, the lower performance
TABLE 4: Elongation at break (\%) of the prepared coatings.

\begin{tabular}{lc}
\hline Sample & Elongation at break (\%) \\
\hline CTRL & 24.8 \\
Coating containing 1 wt\% MCs & 19.4 \\
Coating containing 5 wt\% MCs & 16.25 \\
Coating containing $10 \mathrm{wt} \% \mathrm{MCs}$ & 15.1 \\
\hline
\end{tabular}

of the samples containing 5\% and $10 \%$ MCs may be due to MC agglomeration which will cause porosity in the matrix as well as their negative effect on the adhesion of the coating [44]. In addition, Figure 8 declares passive oxidation for sample CTRL $(\log i \sim-4.5)$ around the surface of scratches which is designated to the constitution of oxidation layer and is detected by constant current despite increasing of potential while for samples containing MCs no passive oxidation observed which could refer to the performance of healing agents via self-healing processes.

The EIS measurements were also carried out on the scratched and immersed coatings to investigate their corrosion properties and healing efficiency [45]. Figure 9 represents the EIS results for these coatings after 14 days of immersion in a $3.5 \% \mathrm{NaCl}$ solution. Regarding the Nyquist diagrams (Figure 9(a)), the diameter of the resulted semicircles is referred to the coating's corrosion resistance; thereby, the largest semicircle diameter is attributed to the highest resistance against corrosion and vice versa. On the other hand, the total impedance vs. frequency is presented in Bode modulus plots (Figure 9(b)) for better analyzing the results and evaluate the total system resistance (@10-2 $\mathrm{Hz}$ ) including the coating's pore resistance and charge transfer resistance [46]. According to the results, a two-time constant electrical equivalent circuit model was also used to analyze the EIS data by the Z-view software (Figure 10) [47, 48]. Rs, CPEcoat, Rpore, Rct, CPEDL, and (n) stand for the electrolyte resistance, coating capacitance, pore resistance, charge transfer resistance, double-layer capacitance, and potential factor, respectively. Constant phase elements (CPE) were used in the electrical equivalent circuit model, owing to the capacitance behavior has some deviations from the pure capacitance in practice. The calculated parameters, according to the proposed circuit models, are presented in Table 6 . The charge transfer resistance (Rct) was used in this research to compare the performance of the coatings since it is associated with the active area of the electrode and the rate at which Faradic processes occur at its interface. Both the higher intrinsic energy barrier of the charge transfer process and the smaller active area of the electrode which limit the electron transfer and corrosion reactions can be observed as higher Rct. In fact, as Rct is inversely proportional to the exposed active area of the electrode (according to the $\mathrm{Ohm}$ law), higher is the Rct, smaller is the area of the underneath metal exposed to the aggressive solution which might be driven by the self-healing reaction occurring in the coating's scratch $[47,49]$. According to the calculated charge transfer resistance, adding $1 \%$ of MCs to the coating formulation increased the Rct dramatically, but it started to decrease by increasing the MC content from $1 \mathrm{wt} \%$. These results were 
TABLE 5: The results of the gloss measurement for prepared coatings.

\begin{tabular}{lccc}
\hline Sample & 20 degrees $(\mathrm{GU})$ & 60 degrees $(\mathrm{GU})$ & 85 degrees $(\mathrm{GU})$ \\
\hline CTRL & $89.7 \pm 2$ & $102.5 \pm 2$ & $57.2 \pm 2$ \\
Coating containing $1 \mathrm{wt} \% \mathrm{MCs}$ & $84.8 \pm 2$ & $100.7 \pm 2$ & $55.8 \pm 2$ \\
Coating containing $5 \mathrm{wt} \% \mathrm{MCs}$ & $79.3 \pm 3$ & $96.4 \pm 3$ & $51.5 \pm 2$ \\
Coating containing $10 \mathrm{wt} \% \mathrm{MCs}$ & $71.3 \pm 2$ & $91.2 \pm 3$ & $47.7 \pm 3$ \\
\hline
\end{tabular}

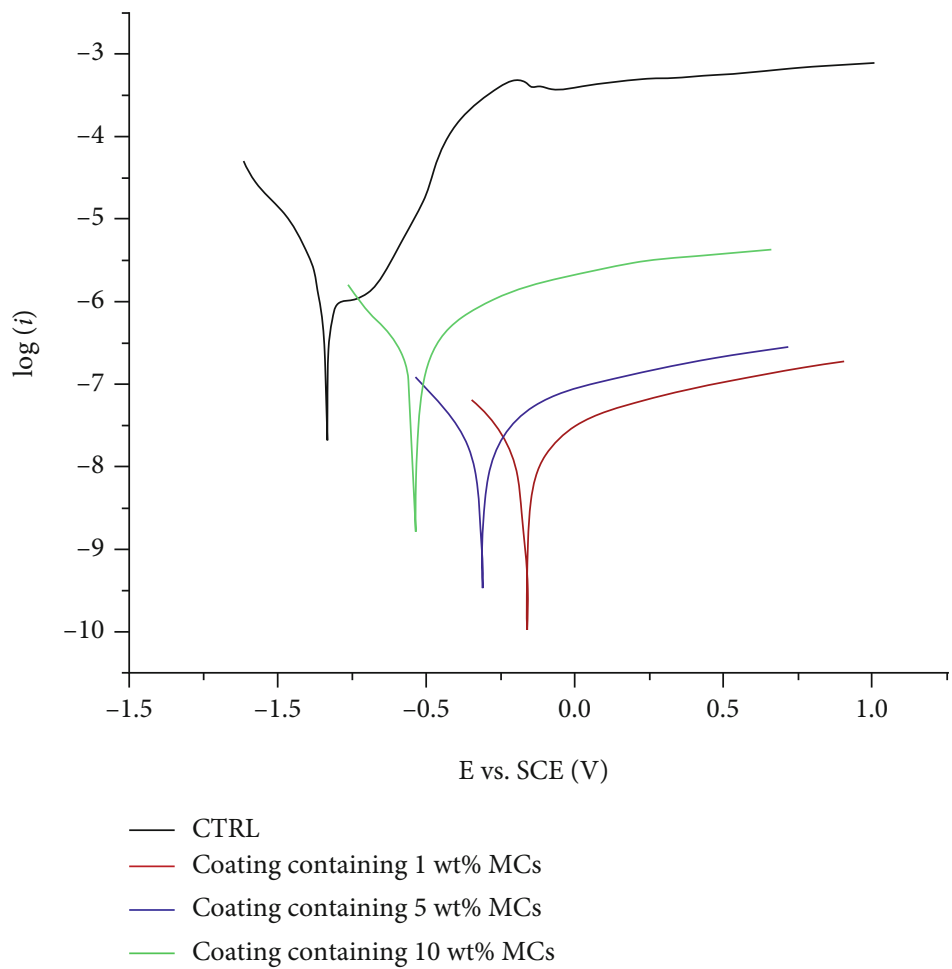

Figure 8: Potentiodynamic polarization curves for the scratched control and $\mathrm{MC}$ contained coatings after 14 days of immersion in $3.5 \% \mathrm{NaCl}$ solution $\left(0.785 \mathrm{~cm}^{2}\right.$ circular contact area).

consistent with previous corrosion resistance experiments. The results showed that the CTRL sample coating (without MCs) did not provide efficient corrosion protection and healing reaction against the electrolyte aggressive media. Although the sample with $10 \%$ MCs was qualified to support the self-healing reaction by releasing the healing agents in scratches, the probable agglomeration of MCs decreased the corrosion resistance by increasing the coating porosity.

The Bode modulus plots presented in Figure 9(b) prove the abovementioned explanations. It should be noted that the impedance modulus values at low frequencies are related to coating-metal interfaces. According to the results, the sample $1 \%$ presented the highest impedance value of $(z)=$ $3.7 \times 10^{6}$ at the lowest frequency which is clearly in good agreement with other evaluation techniques. The good compatibility between potentiodynamic polarization and EIS results confirmed that a $1 \mathrm{wt} \% \mathrm{MC}$ incorporating was adequate to heal the crack and protect the substrate. By comparing the present results with the previous researches, it can be concluded that submicron scale capsules provide sufficient healing at lower amounts of capsule concentration which is one of the most important advantageous achieved in the current research. Bode phase results, presented in Figure 9(c), confirm the other corrosion evaluation results.

The self-healing efficiency (HE) of the samples was calculated by Eq. (3) [50].

$$
\% \mathrm{HE}=\left(1-\frac{\mathrm{Rct}_{0}}{\mathrm{Rct}}\right) \times 100 .
$$

$\mathrm{Rct}_{0}$ and Rct are the charge transfer resistances calculated for the control and self-healing coatings, respectively. According to the results, the maximum HE was calculated to be $99 \%$ for the $1 \mathrm{wt} \%$ sample indicating its superior resistance against corrosion.

SEM was also used on the scratched and immersed coating containing $1 \mathrm{wt} \%$ of MCs to visually investigate the healing process $[45,51]$. Figure 11 shows the micrographs of the scratched coating after healing. It can be seen a thin layer of 


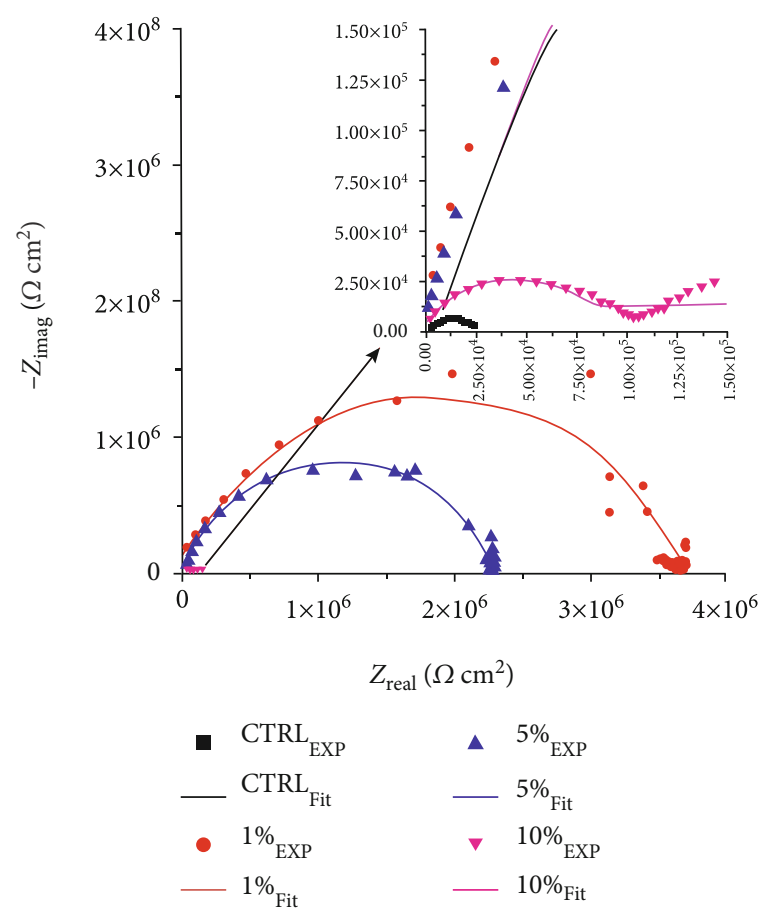

(a)

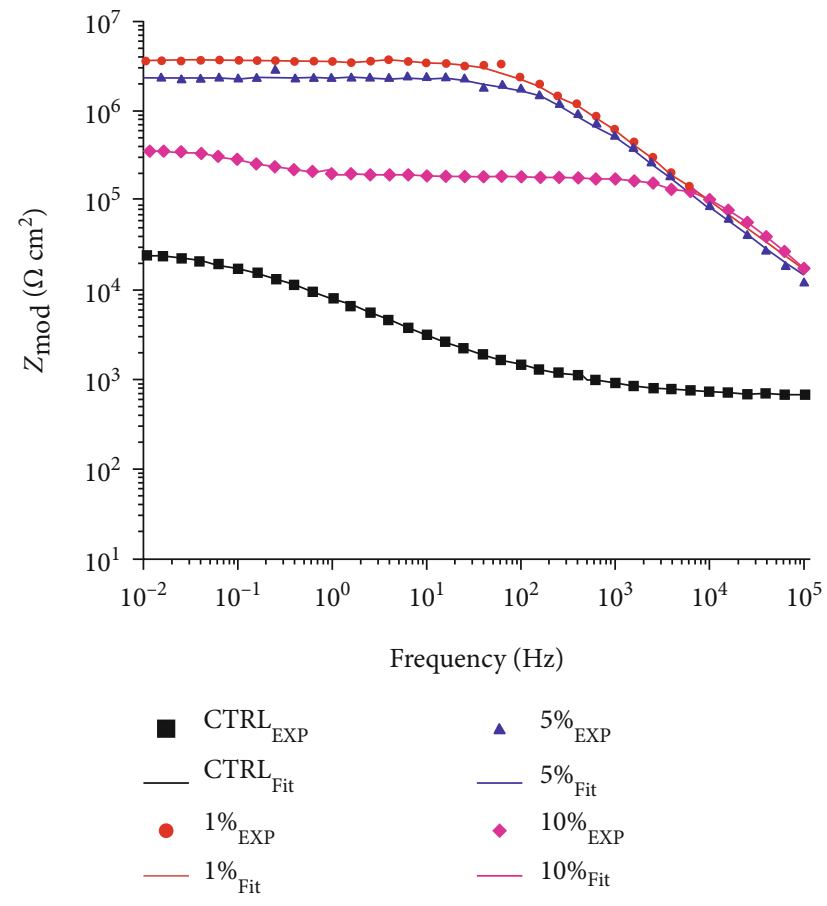

(b)
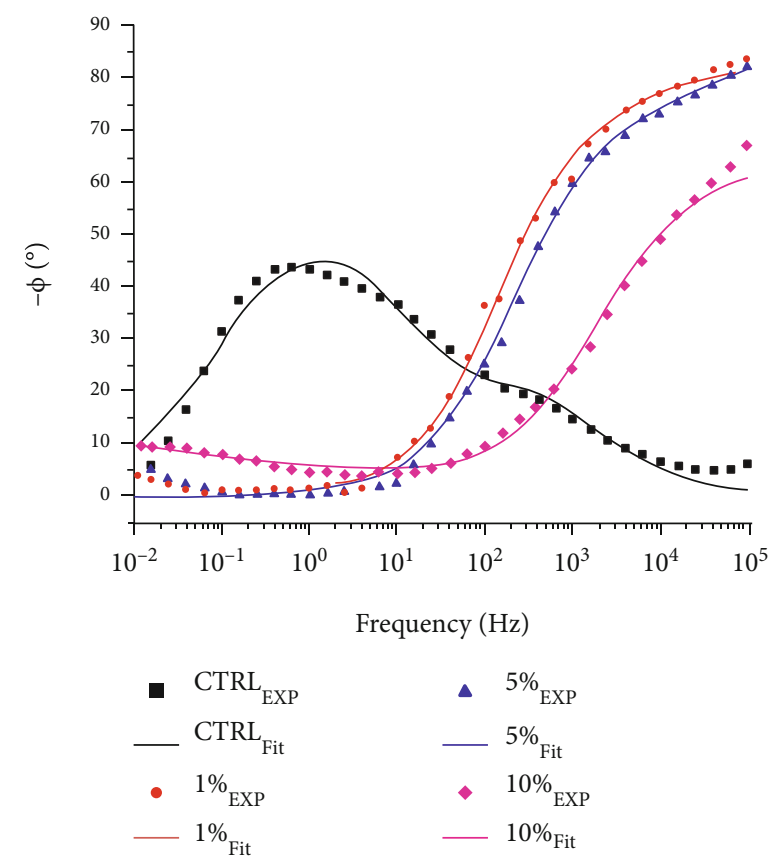

(c)

Figure 9: (a) Nyquist, (b) Bode modulus, and (c) Bode phase, plots of the scratched control and MC contained coatings after 14 days of immersion in $3.5 \% \mathrm{NaCl}$ solution $\left(0.785 \mathrm{~cm}^{2}\right.$ circular contact area).

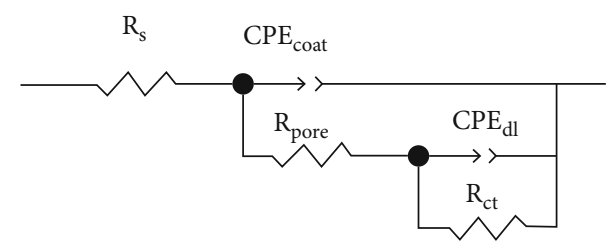

FIGURE 10: The incorporated electrical equivalent circuit model. the healing polymer has been formed in the crack and covered the substrate. According to the SEM image, despite the fact that the released healing agents were not enough to fill the crack completely and provide full mechanical recovery, it sealed the crack with the aforementioned thin layer. This thin formed layer was enough to protect the substrate against the corrosive environment [52]. 
TABLE 6: The EIS parameters for the scratched control and MC containing coatings after being immersed in $3.5 \% \mathrm{NaCl}$ solution for 14 days $\left(0.785 \mathrm{~cm}^{2}\right.$ circular contact area).

\begin{tabular}{|c|c|c|c|c|c|c|c|c|}
\hline Sample & $\begin{array}{c}\text { Rs } \\
\left(\Omega \mathrm{cm}^{2}\right)\end{array}$ & $\begin{array}{c}\text { Qcoat } \\
\left(\operatorname{sn} . \Omega^{-1} \cdot \mathrm{cm}^{-2}\right)\end{array}$ & ncoat & $\begin{array}{c}\text { Rpore } \\
\left(\Omega \mathrm{cm}^{2}\right)\end{array}$ & $\begin{array}{c}\text { Qdl } \\
\left(\operatorname{sn} . \Omega^{-1} \cdot \mathrm{cm}^{-2}\right)\end{array}$ & ndl & $\begin{array}{c}\text { Rct } \\
\left(\Omega \mathrm{cm}^{2}\right)\end{array}$ & $\begin{array}{c}\text { Goodness } \\
\text { of fit }\end{array}$ \\
\hline CTRL & $0.65 E+03$ & $2.46 E-05$ & $5.28 E-01$ & $1.33 E+03$ & $1.60 E-05$ & $5.77 E-01$ & $2.67 E+04$ & $2.12 E-03$ \\
\hline Coating containing $1 \mathrm{wt} \% \mathrm{MCs}$ & $1.51 E+03$ & $6.22 E-09$ & $7.34 E-01$ & $8.89 E+03$ & $8.53 E-09$ & $1.00 E-01$ & $3.79 E+06$ & $2.02 E-03$ \\
\hline Coating containing $5 \mathrm{wt} \% \mathrm{MCs}$ & $1.38 E+03$ & $6.04 E-09$ & $7.31 E-01$ & $1.03 E+04$ & $6.59 E-09$ & $1.00 E-02$ & $2.25 E+06$ & $1.87 E-03$ \\
\hline Coating containing $10 \mathrm{wt} \% \mathrm{MCs}$ & $0.25 E+03$ & $1.65 E-08$ & $7.01 E-01$ & $8.83 E+04$ & $1.85 E-05$ & $3.24 E-01$ & $2.00 E+05$ & $1.41 E-03$ \\
\hline
\end{tabular}

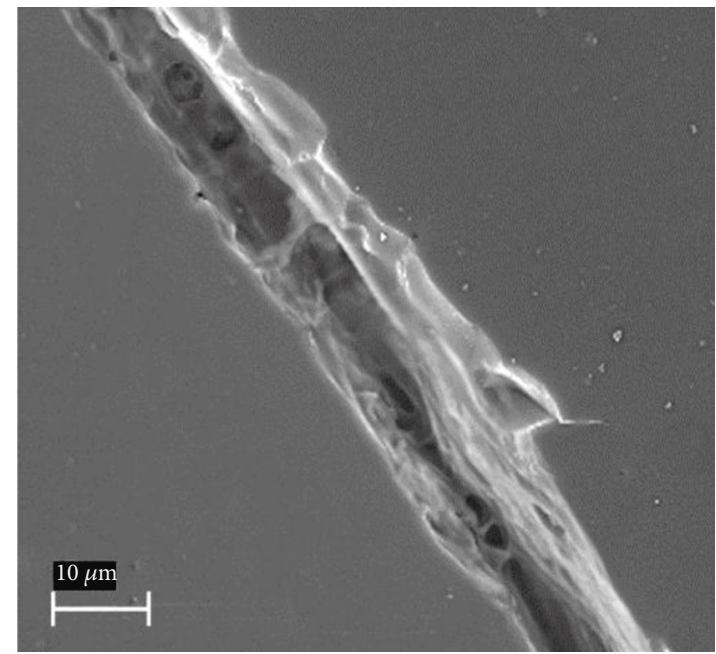

FIGURE 11: SEM micrographs of scratched and immersed coating containing $1 \mathrm{wt} \%$ of MCs after the healing process.
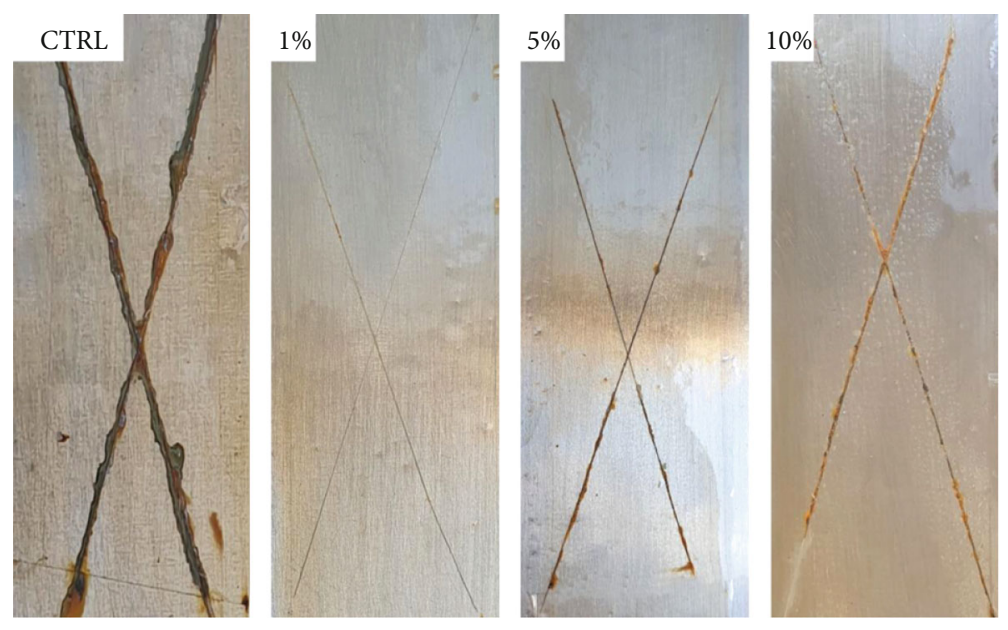

FIgURE 12: Samples after 72 hours of exposure in the salt spray chamber. The control coating and the coatings containing 1,5 , and 10 wt $\%$ MCs.

3.7. Salt Spray Corrosion Test. Figure 12 shows the images of scratched coatings after 72 hours in a salt spray chamber. According to the corrosion rust present in the scratch areas, $\mathrm{MC}$ contained coatings showed better corrosion resistance in comparison with the CTRL sample. This better performance can be referred to the MC rapture and subsequent self-healing reaction provoked by the scratch formation. As can be seen, $1 \%$ sample showed the best performance, but a loss in corrosion resistance was observed for the samples with higher MC content. This lower performance might be due to the negative effect of high MC content on the adhesion strength of the coating which facilitates the corrosive liquid penetration into the metal coating interface [29]. It should be noted that the higher amount of MCs will decrease the adhesion strength due to higher resin adsorption and lower interfacial contact between the substrate metal and the 
matrix [24]. On the other hand, according to salt spray results for samples containing 5 and $10 \% \mathrm{MCs}$, some blisters can be observed on the unscratched area of $5 \%$ and $10 \%$ coatings as a result of $\mathrm{NaCl}$ solution penetration through the pores present in their matrix. The absence of these blisters on the $1 \%$ sample can be referred to the suitable dispersion of MCs in its matrix, while conversely excessive addition of MCs and their further agglomeration led to an increased porosity in the matrix of the $5 \%$ and $10 \%$ samples.

\section{Conclusions}

An extrinsic dual capsule self-healing system was developed for anticorrosion epoxy coatings. Core-shell MCs were prepared by using the emulsion electrospray method. Morphological investigations using SEM showed that core-shell spherical MCs can be prepared by setting the electrospray process parameters. In addition, the average particle size of the prepared capsules containing epoxy resin and the amine core were calculated to be $827 \pm 356 \mathrm{~nm}$ and $749 \pm 190 \mathrm{~nm}$, respectively. The FT-IR spectroscopy results revealed no chemical reactions during the encapsulation process between the SAN shell and both of the core materials. Moreover, the extraction test results revealed that the practical encapsulation yield was obtained to be $73 \%$ and $67.8 \%$ for the epoxy and amine contained MCs, respectively. The corrosion evaluation test results on the scratched coatings showed the sample containing $1 \mathrm{wt} \%$ of core-shell MCs (1:1 by weight mixture of epoxy and amine-containing MCs) provided high corrosion resistance in comparison with the control sample and coatings containing higher capsule contents. The adhesion strength of the prepared coatings to the metal substrate decreased by increasing the amount of MCs, which could be due to the presence of MCs at the matrix-metal interface and reducing the effective contact area. The healing efficiency was calculated to be $99 \%$ for the coating containing $1 \%$ of MCs according to the EIS results.

\section{Data Availability}

The data used to support the findings of this study are available from the corresponding author upon request.

\section{Conflicts of Interest}

The authors declare that there is no conflict of interest regarding the publication of this paper.

\section{References}

[1] V. Amendola and M. Meneghetti, "Self-healing at the nanoscale," Nanoscale, vol. 1, no. 1, pp. 74-88, 2009.

[2] E. Alibakhshi, E. Ghasemi, M. Mahdavian, and B. Ramezanzadeh, "A comparative study on corrosion inhibitive effect of nitrate and phosphate intercalated $\mathrm{Zn}$-Al- layered double hydroxides (LDHs) nanocontainers incorporated into a hybrid silane layer and their effect on cathodic delamination of epoxy topcoat," Corrosion science, vol. 115, pp. 159-174, 2017.

[3] E. Alibakhshi, E. Ghasemi, M. Mahdavian, B. Ramezanzadeh, and S. Farashi, "Active corrosion protection of $\mathrm{Mg}-\mathrm{Al}-\mathrm{PO}_{4}{ }^{3-}$
LDH nanoparticle in silane primer coated with epoxy on mild steel," Journal of the Taiwan Institute of Chemical Engineers, vol. 75, pp. 248-262, 2017.

[4] M. Guo, W. Li, N. Han et al., "Novel dual-component microencapsulated hydrophobic amine and microencapsulated isocyanate used for self-healing anti-corrosion coating," Polymers, vol. 10, no. 3, p. 319, 2018.

[5] C. Zhang, H. Wang, and Q. Zhou, "Preparation and characterization of microcapsules based self-healing coatings containing epoxy ester as healing agent," Progress in organic coatings, vol. 125, pp. 403-410, 2018.

[6] E. K. Karaxi, I. A. Kartsonakis, and C. A. Charitidis, "Assessment of self-healing epoxy-based coatings containing microcapsules applied on hot dipped galvanized steel," Frontiers in Materials, vol. 6, p. 222, 2019.

[7] R. V. S. P. Sanka, B. Krishnakumar, Y. Leterrier, S. Pandey, S. Rana, and V. Michaud, "Soft self-healing Nanocomposites," Frontiers in Materials, vol. 6, p. 137, 2019.

[8] X. Yan, Y. Chang, and X. Qian, "Preparation and self-repairing properties of urea formaldehyde-coated epoxy resin microcapsules," International Journal of Polymer Science, vol. 2019, Article ID 7215783, 11 pages, 2019.

[9] R. Samiee, B. Ramezanzadeh, M. Mahdavian, and E. Alibakhshi, "Assessment of the smart self-healing corrosion protection properties of a water-base hybrid organo-silane film combined with non-toxic organic/inorganic environmentally friendly corrosion inhibitors on mild steel," Journal of cleaner production, vol. 220, pp. 340-356, 2019.

[10] G. Huyang, A. E. Debertin, and J. Sun, "Design and development of self-healing dental composites," Materials \& design, vol. 94, pp. 295-302, 2016.

[11] W. Li, Z. Jiang, Z. Yang, and H. Yu, "Effective mechanical properties of self-healing cement matrices with microcapsules," Materials \& design, vol. 95, pp. 422-430, 2016.

[12] F. Cotting, A. Koebsch, and I. V. Aoki, "Epoxy self-healing coating by encapsulated epoxy ester resin in poly (urea-formaldehyde-melamine) microcapsules," Frontiers in Materials, vol. 6, p. 314, 2019.

[13] R. Esmaeely Neisiany, M. S. Enayati, P. Sajkiewicz, Z. Pahlevanneshan, and S. Ramakrishna, "Insight into the current directions in functionalized nanocomposite hydrogels," Frontiers in materials, vol. 7, p. 25, 2020.

[14] Y. Hao, Y. Zhao, B. Li, L. Song, and Z. Guo, "Self-healing effect of [email protected] loaded with benzotriazole for carbon steel," Corrosion science, vol. 163, article 108246, 2020.

[15] F. Sordo and V. Michaud, "Processing and damage recovery of intrinsic self-healing glass fiber reinforced composites," Smart Materials and Structures, vol. 25, no. 8, article 084012, 2016.

[16] Z. Wang, X. Lu, S. Sun, C. Yu, and H. Xia, "Preparation, characterization and properties of intrinsic self-healing elastomers," Journal of Materials Chemistry B, vol. 7, no. 32, pp. 4876-4926, 2019.

[17] Z. Wang, L. Scheres, H. Xia, and H. Zuilhof, "Developments and challenges in self-healing antifouling materials," Advanced functional materials, vol. 30, no. 26, article 1908098, 2020.

[18] S. K. Ghosh, Self-Healing Materials: Fundamentals, Design Strategies, and Applications, John Wiley \& Sons, 2009.

[19] B. J. Blaiszik, S. L. Kramer, S. C. Olugebefola, J. S. Moore, N. R. Sottos, and S. R. White, "Self-healing polymers and composites," Annual Review of Materials Research, vol. 40, no. 1, pp. $179-211,2010$. 
[20] R. Malekkhouyan, R. E. Neisiany, S. N. Khorasani, O. Das, F. Berto, and S. Ramakrishna, "The influence of size and healing content on the performance of extrinsic self-healing coatings," Journal of Applied Polymer Science, vol. 138, no. 10, p. 49964, 2021.

[21] R. Samiee, B. Ramezanzadeh, M. Mahdavian, E. Alibakhshi, and G. Bahlakeh, "Designing a non-hazardous nano-carrier based on graphene [email protected] (III) for fabrication of the active/passive anti-corrosion coating," Journal of hazardous materials, vol. 398, article 123136, 2020.

[22] A. Habibiyan, B. Ramezanzadeh, M. Mahdavian, G. Bahlakeh, and M. Kasaeian, "Rational assembly of mussel-inspired polydopamine (PDA)-Zn (II) complex nanospheres on graphene oxide framework tailored for robust self-healing anticorrosion coatings application," Chemical Engineering Journal, vol. 391, p. 123630, 2020.

[23] S. R. White, N. R. Sottos, P. H. Geubelle et al., "Autonomic healing of polymer composites," Nature, vol. 409, no. 6822, pp. 794-797, 2001.

[24] R. Malekkhouyan, S. Nouri Khorasani, R. Esmaeely Neisiany, R. Torkaman, S. M. Koochaki, and O. Das, "Preparation and characterization of electrosprayed nanocapsules containing coconut-oil-based alkyd resin for the fabrication of selfhealing epoxy coatings," Applied Sciences, vol. 10, no. 9, p. 3171, 2020.

[25] R. E. Neisiany, M. S. Enayati, A. Kazemi-Beydokhti, O. Das, and S. Ramakrishna, "Multilayered bio-based electrospun membranes: a potential porous media for filtration applications," Frontiers in Materials, vol. 7, p. 67, 2020.

[26] J.-H. Park and P. V. Braun, "Coaxial electrospinning of selfhealing coatings," Advanced Materials, vol. 22, no. 4, pp. 496-499, 2010.

[27] M. W. Lee, S. An, C. Lee, M. Liou, A. L. Yarin, and S. S. Yoon, "Self-healing transparent core-shell nanofiber coatings for anti-corrosive protection," Journal of Materials Chemistry A, vol. 2, no. 19, pp. 7045-7053, 2014.

[28] I. L. Hia, P. Pasbakhsh, E.-S. Chan, and S.-P. Chai, "Electrosprayed multi-core alginate microcapsules as novel selfhealing containers," Scientific Reports, vol. 6, no. 1, p. 34674, 2016.

[29] M. S. Koochaki, S. Nouri Khorasani, R. Esmaeely Neisiany, A. Ashrafi, M. Magni, and S. P. Trasatti, "Facile strategy toward the development of a self-healing coating by electrospray method," Materials Research Express, vol. 6, no. 11, p. 116444, 2019.

[30] S. Ataei, A. Hassan, P. Azari et al., "Electrosprayed PMMA microcapsules containing green soybean oil-based acrylated epoxy and a thiol: a novel resin for smart self-healing coatings," Smart Materials and Structures, vol. 29, no. 8, article 085037, 2020.

[31] R. E. Neisiany, J. K. Y. Lee, S. N. Khorasani, and S. Ramakrishna, "Towards the development of self-healing carbon/epoxy composites with improved potential provided by efficient encapsulation of healing agents in core-shell nanofibers," Polymer testing, vol. 62, pp. 79-87, 2017.

[32] G. Zhao, H. Ni, S. Ren, and G. Fang, "Correlation between solubility parameters and properties of alkali lignin/pva composites," Polymers, vol. 10, no. 3, p. 290, 2018.

[33] E. Rezvani Ghomi, R. Esmaeely Neisiany, S. Nouri Khorasani et al., "Development of an epoxy self-healing coating through the incorporation of acrylic acid-co-acrylamide copolymeric gel," Progress in organic coatings, vol. 149, article 105948, 2020.
[34] R. E. Neisiany, S. N. Khorasani, J. Kong Yoong Lee, and S. Ramakrishna, "Encapsulation of epoxy and amine curing agent in PAN nanofibers by coaxial electrospinning for selfhealing purposes," RSC Advances, vol. 6, no. 74, pp. 7005670063, 2016.

[35] Q. Li, A. K. Mishra, N. H. Kim, T. Kuila, K.-t. Lau, and J. H. Lee, "Effects of processing conditions of poly(methylmethacrylate) encapsulated liquid curing agent on the properties of self-healing composites," Composites Part B: Engineering, vol. 49, pp. 6-15, 2013.

[36] T. J. Mitchell and M. W. Keller, "Coaxial electrospun encapsulation of epoxy for use in self-healing materials," Polymer International, vol. 62, no. 6, pp. 860-866, 2013.

[37] F. Ahangaran, A. H. Navarchian, M. Hayaty, and K. Esmailpour, "Effect of mixing mode and emulsifying agents on micro/nanoencapsulation of low viscosity self-healing agents in polymethyl methacrylate shell," Smart Materials and Structures, vol. 25, no. 9, article 095035, 2016.

[38] L. Vertuccio, S. Russo, M. Raimondo, K. Lafdi, and L. Guadagno, "Influence of carbon nanofillers on the curing kinetics of epoxy-amine resin," RSC Advances, vol. 5, no. 110, pp. 90437-90450, 2015.

[39] D. Raps, T. Hack, M. Kolb, M. Zheludkevich, and O. Nuyken, "Development of corrosion protection coatings for AA2024T3 using micro-encapsulated inhibitors," Smart Coatings III. ACS Publications, 2010.

[40] S. Hatami Boura, M. Peikari, A. Ashrafi, and M. Samadzadeh, "Self-healing ability and adhesion strength of capsule embedded coatings-micro and nano sized capsules containing linseed oil," Progress in Organic Coating, vol. 75, no. 4, pp. 292 300, 2012.

[41] R. Samiee, B. Ramezanzadeh, M. Mahdavian, E. Alibakhshi, and G. Bahlakeh, "Graphene oxide nano-sheets loading with praseodymium cations: adsorption- desorption study, quantum mechanics calculations and dual active-barrier effect for smart coatings fabrication," Journal of industrial and engineering chemistry, vol. 78, pp. 143-154, 2019.

[42] S. U. Rahman and A. Atta Ogwu, "Corrosion and MottSchottky probe of chromium nitride coatings exposed to saline solution for engineering and biomedical applications," in advances in medical and surgical engineering, W. Ahmed, D. A. Phoenix, M. J. Jackson, and C. P. Charalambous, Eds., pp. 239-265, Academic press, 2020.

[43] S. Neuser, P. W. Chen, A. R. Studart, and V. Michaud, "Fracture toughness healing in epoxy containing both epoxy and amine loaded capsules," Advanced Engineering Materials, vol. 16, no. 5, pp. 581-587, 2014.

[44] X. Liu, H. Zhang, J. Wang, Z. Wang, and S. Wang, "Preparation of epoxy microcapsule based self-healing coatings and their behavior," Surface and coatings technology, vol. 206, no. 23, pp. 4976-4980, 2012.

[45] M. S. Koochaki, S. N. Khorasani, R. E. Neisiany, A. Ashrafi, S. P. Trasatti, and M. Magni, "A highly responsive healing agent for the autonomous repair of anti-corrosion coatings on wet surfaces. In operando assessment of the self-healing process," Journal of Materials Science, vol. 56, no. 2, pp. 1794-1813, 2021.

[46] E. Bakhshandeh, A. Jannesari, Z. Ranjbar, S. Sobhani, and M. R. Saeb, "Anti-corrosion hybrid coatings based on epoxysilica nano-composites: toward relationship between the morphology and EIS data," Progress in Organic Coatings, vol. 77, no. 7, pp. 1169-1183, 2014. 
[47] W. Wang, L. Xu, X. Li, Z. Lin, Y. Yang, and E. An, "Self-healing mechanisms of water triggered smart coating in seawater," Journal of Materials Chemistry A, vol. 2, no. 6, pp. 19141921, 2014.

[48] M. Hasanzadeh, M. Shahidi, and M. Kazemipour, "Application of EIS and EN techniques to investigate the self-healing ability of coatings based on microcapsules filled with linseed oil and $\mathrm{CeO}_{2}$ nanoparticles," Progress in Organic Coatings, vol. 80, pp. 106-119, 2015.

[49] E. R. Ghomi, S. N. Khorasani, M. K. Kichi et al., "Synthesis and characterization of $\mathrm{TiO} 2 /$ acrylic acid-co-2-acrylamido-2methyl propane sulfonic acid nanogel composite and investigation its self-healing performance in the epoxy coatings," Colloid and Polymer Science, vol. 298, no. 2, pp. 213-223, 2020.

[50] A. M. Atta, O. E. el-Azabawy, H. Ismail, and M. Hegazy, "Novel dispersed magnetite core-shell nanogel polymers as corrosion inhibitors for carbon steel in acidic medium," Corrosion Science, vol. 53, no. 5, pp. 1680-1689, 2011.

[51] H. Li, Y. Cui, Z. Li, Y. Zhu, and H. Wang, "Fabrication of microcapsules containing dual-functional tung oil and properties suitable for self-healing and self-lubricating coatings," Progress in organic coatings, vol. 115, pp. 164-171, 2018.

[52] S. H. Cho, H. M. Andersson, S. R. White, N. R. Sottos, and P. V. Braun, "Polydimethylsiloxane-based self-healing materials," Advanced materials, vol. 18, no. 8, pp. 997-1000, 2006. 